\title{
An investigation into the routes to inpatient care at the Pantang Hospital in Ghana via the criminal justice system
}

\author{
Tracey A. Bone ${ }^{1}$ and Mark Roberts ${ }^{2}$
}

Ghana Med J 2019; 53(2): 100-108 doi: http://dx.doi.org/10.4314/gmj.v53i2.4

\author{
${ }^{1}$ Faculty of Social Work, University of Manitoba, Winnipeg, Manitoba, R3T 2N2, Canada \\ ${ }^{2}$ Faculty of Research and Knowledge Exchange, University of Winchester, SO22 4NR, United Kingdom
}

\author{
Corresponding author: Tracey A. Bone \\ Conflict of interest: None declared
}

E-mail: Tracey.bone@umanitoba.ca

\section{SUMMARY}

Objectives: To develop knowledge of routes by which patients are admitted to Pantang hospital via the courts or police and to explore the factors that prevent discharge, rehabilitation or transfer to prison of these patients.

Setting: Pantang Psychiatric Hospital, Accra, Ghana, West Africa

Design: A cross-sectional exploratory qualitative study.

Participants: Adult patients with a psychiatric diagnosis who had been admitted to hospital following involvement with the criminal justice system and their families; and stakeholders (participants who had experience working with mentally disordered offenders).

Methods: A descriptive and ethnographic survey of patients plus interviews with key stakeholders in mental health and criminal justice. Data were analysed using hybrid thematic analysis.

Results: Patients arrived at Pantang Psychiatric Hospital following referral by the arresting police authorities, through court referral, or directly from prisons. All participants reported lack of understanding of the mental health and criminal justice systems, and interface between the two. Most patients and family members reported they feared the stigma of mental illness and patients' criminal charges would interrupt the patients' successful reintegration into the community.

Conclusion: This study revealed that forensic mental health patients in the Pantang Hospital entered through one of three ways; direct entry through the community-based policing system; on order through the court system; and referrals directly from the prison system. Inadequate staffing and other resources resulted in delays in completing the necessary psychiatric assessments.

Keywords: Inpatient psychiatric care, forensic mental health, stigma, Ghana, psychiatry Funding: The study was funded locally and by a grant received from the Faculty of Forensic Psychiatry, Royal College of Psychiatrists in the UK.

\section{INTRODUCTION}

It is estimated that of the 24.3 million people living in Ghana, approximately 2.4 million live with mental illness ${ }^{1}$ and nearly $20 \%$ of the population experience psychological distress at a level that is considered either moderate or severe. ${ }^{2}$ In 2011 Ghana had three main psychiatric hospitals, 123 mental health outpatient facilities, seven community-based psychiatric inpatient units, four community residential facilities, and one day-treatment center. ${ }^{3}$ The majority of beds for psychiatric patients were provided in the 3 psychiatric hospitals, all clustered in southern Ghana. ${ }^{4}$ In 2011 there were a total of 1,322 physical beds available in these three facilities with 441 of the total recorded in Pantang Hospital. ${ }^{5}$ Since their inception the psychiatric hospitals in Ghana have suffered from chronic over-crowding, with some patients remaining in hospital beyond the time for discharge not due to need, but to abandonment by families. This abandonment can result from mental health stigma, discrimination and inadequate community-based supports and treatment. In 2011 staffing of the mental health system included 18 psychiatrists, 72 Community Mental Health Officers, 1,256 nurses, 19 psychologists, and 21 social workers. ${ }^{6}$

In 2012 Ghana passed a new and progressive Mental Health Act, (Act 826). The new law is intended to ensure that appropriate, timely and comprehensive mental health care is provided to those persons who live with mental illness, and to provide clear direction to ensure the human rights of persons with mental disorders will be protected. 
Of particular interest are vulnerable groups who live with mental disorders such as women, children, and offenders with mental disorders. ${ }^{7,8}$ This Act focuses on transitioning the mode of mental health care from the current predominately institutional care to community-based care. The first step towards implementing the new Act occurred in November 2013 with the formal appointment of Ghana's Mental Health Board. ${ }^{9}$ The first task of this Board is to create a Legislative Instrument that will be the guiding document in their work. ${ }^{10}$

There is much optimism surrounding the implementation of the new Act, though a number of challenges are noted. Concerns include organizational challenges, human resource deficits, an inadequate social service infrastructure, legal and judicial framework, and unsophisticated information systems. ${ }^{11}$

\section{Mental illness and criminal justice in Ghana}

It is reported that, in general, people with severe mental illnesses, including schizophrenia, bipolar disorder and/or psychosis, "are $2 \frac{1}{2}$ times more likely to be attacked, raped or mugged than the general population". ${ }^{12}$ Notwithstanding these figures, there is an important subgroup of mental health patients who have committed crimes or are suspected of doing so.

There is a paucity of literature studying the topic of mental health and policing in Africa. ${ }^{13}$ Wolfe ${ }^{14}$ reports that management of mental health crisis situations is more effective when "there is a close formal liaison between police services and mental health systems" (as cited in Chappell, p. 294). The absence of formal mental health training for police, lawyers or judges however, prevents appropriate management of mental health cases through the criminal justice system. ${ }^{15}$ In Ghana, it is estimated that a mere $2 \%$ of prisoners who require it, actually have contact with a mental health professional while incarcerated. $^{1}$

\section{The criminal code and mental illness}

Criminal offences in Ghana are currently separated into three primary categories namely, offences against the person (Criminal Code, 2003 - Part II), offences against property (Part III), and offences against public order, health and morality (Part IV). ${ }^{17}$ Of relevance to this study is Section 27- When an Insane Person is Entitled to Special Verdict. This section reads as follows:

When a person is accused of crime, the special verdict provided by the Criminal Procedure Code in the case of insanity shall only be applicable;

(a) if he was prevented, by reason of idiocy, imbecility, or any mental derangement or disease affecting the mind, from knowing the nature or consequences of the act in respect of which he is accused; or (b) if he did the act in respect of which he is accused under the influence of an insane delusion of such a nature as to render him, in the opinion of the jury or of the Court, an unfit subject for punishment of any kind in respect of such act.

The aim of this study was to explore the routes through which individuals entered the Pantang Psychiatric Hospital when suspicion or evidence of mental illness was a factor.

\section{METHODS}

This study received ethical approval from the Ghana Health Service Ethical Review Committee. Ethical Clearance - ID NO: GHS-ERC:05/11/11. All participants went through the required informed consent procedure.

\section{Field work setting}

Pantang Psychiatric Hospital is located in the village of Pantang, 20 kilometers from the center of Accra in the Ga East Municipal Assembly of the Greater Accra Region of Ghana. Commissioned in 1975, it was the third built of the three psychiatric hospitals in the Republic of Ghana. Originally planned as a regional psychiatric hospital with a bed capacity of 500, the site currently operates 28 departments. Services include both psychiatric and medical Out Patient Departments (OPDs), as well as psychiatric In-Patient services.

The mental health system in Ghana uses the International Classification of Diseases (ICD) - 10 for psychiatric diagnoses. In 2012 Pantang Psychiatric Hospital reported a total of 1,337 admissions. The top five causes for admission in 2012 were schizophrenia, schizotypal and delusional disorders; mental disorders due to cannabis use; depression and mood disorders; mental disorders due to alcohol use; and mental disorders due to psychoactive substances. ${ }^{18}$ The hospital inpatient occupancy rate on 18th November 2013, during the data collection period, was 221 .

\section{Study design}

This study was a cross-sectional exploratory qualitative study. The study population consisted of two groups:

- In-patients at Pantang Psychiatric Hospital who were on court order for psychiatric assessment and/or treatment (and family members of these patients).

- Stakeholders including select hospital staff, one representative each of two non-governmental organizations, a local police and local court representative, and the Chief Psychiatrist for Ghana. 


\section{Data collection}

The main data collection tool was a semi-structured interview guide designed specifically for each group of participants. All patient, family and hospital staff interviews occurred on the grounds of the hospital; stakeholder interviews occurred off site. In the case of the lawyer, a copy of the interview guide was forwarded electronically and responded to electronically.

All patients who met the inclusion criteria were invited to participate. Participants were excluded if they were unable to speak one of the two languages of the research team (English and Twi) or were too unwell either by selfreport or nursing observation to respond to the questions posed. The nursing preceptor at Pantang Hospital identified inpatients that met the inclusion criteria. The research team then reviewed the records prior to interview to obtain details necessary to inform interviews.

All in-depth interviews occurred over a one-month period between mid-November/mid-December 2013. All interviews were conducted in either English (by the Researcher) or in local language Twi (by the Research Assistant [RA]) or a combination thereof. All were audio recorded with the permission of the participant. All interviews lasted between 45-75 minutes. Written consent was obtained from all participants. On the request of the Medical Director, a ward nursing staff attended as witness during the informed consent procedure to ensure understanding by the patient. All interviews conducted in Twi were translated into English by one of two RAs involved in the study.

\section{Data Analysis}

Analysis occurred through a hybrid approach of inductive and deductive coding and theme development. ${ }^{19} \mathrm{~A}$ preliminary review of the interview data began immediately following each interview. Initial thoughts of the Researcher and Research Assistant were recorded in field notes and those notes were reviewed while analyzing each participant's transcript. An initial round of inductive coding followed each interview. Each subsequent interview was coded based on that individual content, and later added to the cross case analysis. Once all the data had been coded, emerging themes were reviewed; some of these themes were aggregated as appropriate.

\section{Study limitations}

The main limitation was that the patient sample was all male. It is possible that the experiences for female psychiatric patients entering through the criminal justice system could be different from that of male patients.
The study was conducted at only one of the three psychiatric hospitals; it is possible that the experiences at different hospitals or psychiatric units in Ghana could be different. In many cases, hospital records did not have complete historical data or court documents. Additional file documentation may have provided different insights into the experiences of the patients. There may have been an influence on participation by virtue of the Principal Researcher being a white, female, Canadian. Some participants may have been cautious about revealing personal information to a foreigner, particularly about an issue that carries great stigma in the country. The full impact of the interviewer's characteristics is not clear.

Finally, the process of translation always brings with it the possibility of some loss or distortion of meaning from the original. As a result of these issues, whilst the findings are useful, they cannot be generalized to all psychiatric patients who enter hospital from the criminal justice system.

\section{RESULTS}

Fifteen patients met the study entry criteria and 13 were interviewed. One was not interviewed, as he did not speak either of the two languages of the research team; the second was deemed by staff to be unable to provide informed consent due to his reduced intellectual capacity. All were male. They ranged in age from $23-65$ with a median age of 41.7. The largest ethnic group was Ewe (N $=5$ ). See Table 1 Socio-demographic information - participants for full details.

A total of 24 interviews were conducted: 13 individual inpatient interviews; four family-member interviews; three staff interviews at Pantang Hospital; two with NGO representatives; a police detective; and the Chief Psychiatrist for Ghana. In addition, e-mail responses were received from a judge and lawyer in Accra.

The dominant participant diagnosis as reported in the charts was schizophrenia $(\mathrm{N}=8)$. Of this group, four patients were more specifically categorized with paranoid schizophrenia $(\mathrm{N}=4)$, and two with 'chronic' schizophrenia $(\mathrm{N}=2)$. The authors acknowledge that schizophrenia is generally a chronic disorder, and that "chronic schizophrenia' is not a formal diagnostic classification used in Psychiatry (either DSM-IV-TR [2000 ${ }^{20}$ or ICD $\left.-10[2013]^{21}\right)$. Staff, however, was not aware of any additional details that could have clarified the diagnosis beyond that of 'chronic' schizophrenia for either of these participants. As such, this detail is provided here for information purposes only. 
Of the remaining participants, one patient was diagnosed with mental retardation, and two with mental and behavioural disorder due to psychoactive substances (cannabis). A formal diagnosis was not reported in the chart of the final two participants; with one of these reporting that staff informed him simply he had a "sickness" or "fever".

Table 1 Socio-demographic characteristics of participants

\begin{tabular}{|c|c|}
\hline Variable & Frequency $(\%)^{\mathrm{a}}$ \\
\hline $\begin{array}{l}\text { 1. Gender } \\
\text { Male }\end{array}$ & $13(100 \%)$ \\
\hline $\begin{array}{l}\text { 2. Marital status } \\
\text { Married } \\
\text { Never married } \\
\text { Divorced }\end{array}$ & $\begin{array}{l}1(7 \%) \\
11(85 \%) \\
1(7 \%)\end{array}$ \\
\hline $\begin{array}{l}\text { 3. Education } \\
\text { Formal education } \\
\text { No formal education } \\
\text { Not reported }\end{array}$ & $\begin{array}{l}9(70 \%) \\
2(15 \%) \\
2(15 \%)\end{array}$ \\
\hline $\begin{array}{l}\text { 4. Religion } \\
\text { Christian } \\
\text { Traditionalist } \\
\text { Muslim }\end{array}$ & $\begin{array}{l}10(77 \%) \\
2(15 \%) \\
1(7 \%)\end{array}$ \\
\hline $\begin{array}{l}\text { 5. Diagnoses } \\
\text { Schizophrenia } \\
\text { Mental retardation } \\
\text { Cannabis user } \\
\text { Not reported }\end{array}$ & $\begin{array}{l}8(62 \%) \\
1(7 \%) \\
2(15 \%) \\
2(15 \%)\end{array}$ \\
\hline $\begin{array}{l}\text { 6. Type of offence } \\
\text { Intent or threat to kill } \\
\text { Assault related } \\
\text { Sexual offence } \\
\text { Property related }\end{array}$ & $\begin{array}{l}3(23 \%) \\
7(54 \%) \\
2(15 \%) \\
1(7 \%)\end{array}$ \\
\hline $\begin{array}{l}\text { 7. Previous hospitalizations } \\
\text { None } \\
1-3 \\
4 \text { or more }\end{array}$ & $\begin{array}{l}2(15 \%) \\
11(85 \%) \\
0\end{array}$ \\
\hline $\begin{array}{l}\text { 8. Parental occupations } \\
\text { Both - professional occupations } \\
\text { One - professional occupation } \\
\text { Farmer } \\
\text { Other local employment }\end{array}$ & $\begin{array}{l}3(23 \%) \\
2(15 \%) \\
3(23 \%) \\
5(38 \%)\end{array}$ \\
\hline $\begin{array}{l}\text { 9. Court order (at time of study) } \\
\text { On file } \\
\text { Not on file }\end{array}$ & $\begin{array}{l}10(77 \%) \\
3(23 \%)\end{array}$ \\
\hline
\end{tabular}

${ }^{a}$ Frequencies may not equal $100 \%$ due to rounding.

${ }^{\text {b}}$ Diagnoses as originally reported on participant's hospital chart. Diagnoses were inconsistently reported across the participants' charts. In some cases the diagnosis was reported using DSM 4 or ICD-10 diagnostic classifications, in some cases a diagnosis was reported without an accompanying code, and in two cases no formal diagnostic category was reported.

\section{RESULTS}

The themes reported below are supported by representative quotes.

Theme 1 - Pathways to Pantang Psychiatric Hospital The participants in this study arrived at Pantang Psychiatric Hospital through a variety of channels. Eleven entered directly through the court system after being charged with a criminal offence; two were placed there following conviction.

For those charged, the persons had been charged with or suspected of criminal behavior in their home community. This behavior led to their involvement with the local police service and appearance in court. In three of the eleven cases the accused's courtroom behavior was viewed as aggressive or bizarre by the presiding judge, and, as a result of that behavior the judge directed those individuals to Pantang Hospital for assessment and/or treatment. If an accused had previously been in a psychiatric hospital, and had a hospital 'patient card', that card was presented to the judge and the judge directed those patients to Pantang Hospital for assessment.

At Pantang, most of the participant patients were awaiting completion of their assessment report before their return to court to deal with allegations. As reported by the participants, their actions ranged from damage to property (broken window on small public transport vehicle) to violence against a person. The latter included stabbing a neighbor, hitting a person with a blunt object, rape (of a 15 year old girl), defilement of a male child under sixteen years of age and an attempt murder. In two of the thirteen cases, death had occurred (Case 1: alleged killing of a 'friend' with a cutlass; Case 2: alleged killing of an elderly female relative with a traditional pounding stick, otherwise referred to as a 'fufu pounding stick').

Two of those interviewed were convicted offenders on transfer from a Ghanaian prison. One patient had been detained in Kumasi Prison for four years on remand status before his transfer to Pantang Psychiatric Hospital in May 1998. He was transferred to Pantang for assessment when his institutional behavior became unpredictable. He reported his situation this way,

"I had a murder case and was sent to Kumasi. They asked me to go on remand for a week but nobody came around for four years. After four years I was brought here. It is the prison guards who brought me, I did not hear the judge saying I should be brought here."

Patient, age 56

This experience resulted in significant distress and confusion for this patient. He felt he was being unreasonably detained at Pantang and saw no prospect of change in his situation in the near future. In five of the eleven cases from the community, family members themselves provided escort from the court to the hospital. In the absence of an ambulance service or other medical transport system, these families engaged public transport, be it taxi, small public transport vehicle or combination thereof, to 


\section{Original Article}

escort their often-agitated, and potentially psychotic family member to the hospital. In one case, the patient and family member arrived at midnight via public transport expecting immediate admission. The patient reported, with frustration, however, that they had to wait until the following morning for admission. The majority of patients interviewed reported they were unaware of their mental health diagnosis, court status, or expectations of discharge.

Three of the thirteen patients interviewed did not have a court order in their medical folder, or otherwise available on the ward at the time of the data collection period. An initial request was made of the Pantang Psychiatric Hospital staff for the documents during the data collection period. A second request was made some ten months later. The documents were not made available at that time, or anytime thereafter.

Of those interviewed, one had been formally discharged from Pantang Psychiatric Hospital in July 2013. He continued to be detained at the hospital, however, following a staff-reported escape the night prior to his discharge, an accusation he denied. A second participant had also been formally discharged but remained at the hospital due to what was reported in the chart as 'abandonment by his family'. Staff clarified that the hospital will allow a person to leave the facility following discharge if they have a formal residence to discharge that patient to. In this case, the patient's family refused to visit or provide an address for the patient, so he remained at the Pantang Psychiatric Hospital beyond his discharge date.

\section{Theme 2: Associated burdens of mental illness}

The two most frequently cited burdens of mental illness were stigma, and the unexpected financial obligations associated with involvement in the criminal justice/mental health interface.

Theme 2.1: Stigma The stigma of mental illness was raised as a factor potentially impacting the patient's successful transition back to the community. Patients, family members, and stakeholders all reported that the stigma of mental illness was a factor that led to self-stigma and interrupted health and mental health care seeking behaviors. Some family members also reported concerns the local community may perceive their family member to be a dangerous person given their involvement with the criminal justice system.

One father described a high level of concern regarding the burden of caring for his adult son given the stigma of mental illness, fear of being dangerous, and absence of community-based supports. He stated,
"We're supposed to take care of them. See, they are here and there's no remedy. We will take care of them after they leave her. But that is my worry, ... what happens to them when I die? Especially at night you're supposed to watch them. And when they want to throw something it's not easy. You need someone to help. If there's no one to come to your aid someone on duty somewhere, what will happen?

Patient's father, Patient age 36

Families feared their family member would experience social rejection, challenges in social adjustment, and employment discrimination upon their discharge from the hospital due the added stigma associated with involvement in the criminal justice system. This resulted from concerns of the patient being a potential physical risk to others.

Theme 2.2: Financial expectations Most patients and/or family members reported that financial burdens resulted from transportation (i.e. fuel costs associated with transportation from the scene of the alleged incident to the police station, from police station to court, and/or transportation from court to the Pantang Psychiatric Hospital). Some family members reported they were also expected to cover fuel costs when transportation was provided for their family member by police members directly. Families were also expected to cover food costs for the patient while in police custody, within the hospital setting, and for the officer or officers transporting their family member to the hospital.

One family reported and additional burden from the victim's family who demanded they cover the costs associated with a medical assessment, medication related to the young victim of their family member, as well as transportation costs for the victim and her family to court. The victim's family had independently created a ledger of expenses and presented that to the family of the accused. The sister explained it this way,

"Even the victim's family gave us a bill to pay...my sister went with some money because we didn't know what would happen. My sister gave them 1.5 million old Cedis, that is 150 Ghana Cedis because they had presented a whole bill.... later when we went to court we realized that, no! This case is a legal issue so why should we give out money for each other...so in fact after parting out that 1.5 we decided not to pay anything even though they brought a bill of about 7 million (old Cedis), that is going to be about 300 and something Cedis."

Sister, Patient age 52 


\section{Original Article}

The family above, reported the pressure from the victim's family to cover medical costs as an unexpected and unwelcome burden. They advised that their lack of understanding of the law in relation to the forensic mental health system contributed to their financial burden as they assumed, they were obligated to cover the medical costs of the alleged victim. After consulting their brother's lawyer, they terminated their financial support of the victim's costs as instructed. These sisters reported that in the absence of an easily accessible professional or community-based forensic mental health agency to guide them, they were left to struggle in their decision-making.

\section{Theme 3: Human resource constraints}

Following arrival at Pantang Hospital, lack of human resources impacted the patients' path out of the psychiatric hospital. Two nursing staff interviewed at Pantang Psychiatric Hospital reported that too few psychiatrists resulted in delays to the completion of assessment reports and by extension, the patients return to court for a review. The records reviewed for this study confirmed that several patients had been waiting for weeks for a psychiatric assessment, others for months. One patient's court order expired December 14, 2012, a second was due in court March 5, 2013, though neither were taken to court for their designated court date. In three cases, the patients were within days of their original court ordered re-appearance date, though they had not yet been scheduled to participate in the requisite psychiatric assessment.

On preliminary investigation, it appears that human resource constraints in the Ghana Police Service contributed to unnecessary detentions in the psychiatric hospital for some participants interviewed. As reported by the Ghanaian police representative, the policy regarding case reassignment within the police service is poorly defined. As a result, cases with outstanding court orders are not immediately reassigned, and become a low priority for that particular police detachment. Without reassignment, accused persons with outstanding assessment-related court orders are not followed up. In some cases, the accused remained at the Pantang Psychiatric Hospital as the case had not been reassigned to a new officer.

Several patients reported complications to pre-existing health conditions or newly developed medical conditions that went unaddressed as a result of the delays in receiving primary health care services while an inpatient. One participant reported the need for glasses, another need for dental work. Four other participants reported they often went without their prescribed medications because they simply did not have sufficient funds to purchase the medication themselves.
Participants felt their needs went unattended because of insufficient staffing within the facility. Participants felt additional staff were needed to ensure appropriate primary health care within the psychiatric hospital setting.

\section{Theme 4. Inadequate record keeping}

The issue of record-keeping appeared to contribute to poor patient management. All patient records reviewed were predominantly hand-written. Many entries were illegible, appeared mechanical in the content repetition, and/or lacked sufficient detail to be comprehensive. There were inconsistencies across the participants' files with some lacking information on criminal justice history or current offence, and three lacked copies of current court orders. These are essential documents in the management of forensic patients, particularly those who may have a history of violence or propensity to violence. Finally, patient files were shelved in an open area on the ward in a location that was easily accessible to staff, though also patients and visitors.

\section{Theme 5. Professional development needs}

Staff reported a lack of necessary foundational knowledge and training to work in the field of forensic mental health. They felt the training gaps significantly impacted the type and level of care they could provide. They reported inadequate training in areas such as basic risk assessment and risk management strategies which hindered their ability to provide good quality care. Staff also reported a lack of knowledge regarding available community-based resources that hindered discharge planning.

Staff reported that they would welcome comprehensive training in the areas of prisons, criminal law, and the specific field of forensic mental health so they could feel better prepared to work in the field. Stakeholders, too, reported that their incomplete understanding of the criminal justice and mental health interface hindered their ability to provide quality care to those involved in both fields. They unanimously supported a countrywide psycho-education approach to enhance the country's literacy regarding the mental health/criminal justice interface.

They supported a goal of reducing the stigma associated with psychiatric offenders such that stigma and discrimination of this population no longer impact reintegration. All stakeholders also recommended an increase in professional networking opportunities. They felt disempowered by the lack of opportunities to engage with other professionals in the field and to gain the requisite skills to work within the mental health criminal justice interface. 


\section{DISCUSSION}

This study provided an opportunity to gain a better understanding of the experiences of a sample of individuals involved in the interface between the criminal justice and inpatient mental health system. The majority of patients interviewed reported they were unaware of their mental health diagnosis, court status, or expectations of discharge. They were frustrated with the lack of information and appeared disempowered to create change.

Family members reported frustration with a lack of engagement with staff able to provide current information regarding the state of their family members' mental health status, criminal justice status, treatment plan, and discharge plans. Families reported the unexpected financial burden associated with their family members' incarceration caused them distress. They too expressed concern that the community from which their family member came may in fact reject them upon discharge because of concerns regarding potential risk given their involvement with the court system.

Participants, family members, staff, and stakeholders alike discussed a feeling of impotence in fully comprehending the interface between the criminal justice and mental health systems. They collectively acknowledged that engagement in the mental health system brought great stigma for that person and his or her family. They too acknowledged that communities were often not receptive to receive a community member back into the community following involvement with the mental health system because of misunderstanding of mental illness. Participants felt stigma was further enhanced when also involved in the criminal justice system.

Hospital staff reported a lack of foundational knowledge and training to work effectively within the field of forensic mental health. Staff reported a lack of awareness of the workings and policies of the criminal justice system, and a gap in familiarity with risk, risk assessment or risk management strategies. They felt these gaps significantly impacted the type and level of care they could provide, and placed staff at risk for situational violence within the psychiatric hospital setting. It also placed other patients at risk if appropriate risk management strategies were not in place.

Finally, these gaps placed the public at risk when staff failed to acknowledge the potential harm posed by certain patients following release into the community or absconding from the hospital. The various stakeholders offered a number of recommendations to facilitate safe and effective care to forensic mental health patients.
Cross-training of mental health and criminal justice staff on the dynamics of the criminal justice mental health interface was suggested to facilitate the ability of both to interface effectively across these two systems. This would also provide psychiatric hospital staff with the knowledge necessary to engage effectively with patients, their families, and community on mental health and criminal justice matters.

\section{Recommendations for forensic mental health curric- ulum}

A number of recommendations are forwarded. The field of forensic mental health is a specialized one requiring unique skills and knowledge. Practice must balance the rights and needs of the patient, with the rights and needs of the community at large. ${ }^{22}$ The fundamental factor revealed is the lack of an efficient interface between the mental health and relevant criminal justice partners. This impacted the efficient transfer of information between arresting police and the psychiatric hospital, and the return transfer of patients to court as per the court order. A comprehensive and collaborative approach would facilitate safe, humane, effective and high quality care to patients. Specialized training in the area of forensic mental health across sectors could enhance the necessary collaboration between the systems and support efficient and timely discharge.

It is recommended that training across all partners include content on the current mental health act, as well as the missions and mandates all areas of the criminal justice systems including the judiciary, police and prison systems. Also important is training related to risk assessment and risk management, offender/patient management strategies, non-violent crisis intervention, and personal safety skills training for staff. Training in these areas would provide a secure foundation on which to build a collaborative practice and support discharge, rehabilitation or transfer.

In addition, it is recommended that both sides of the interface, mental health and criminal justice, develop collaborative policies and strategies for the management of the 'mentally disordered offender.' All departments within the field of forensic mental health must be made aware of the stigma associated with mental illness and the additional burden for those also involved in the criminal justice system.

Collaboration between the courts, policing services, and the psychiatric hospitals would enhance understanding across sectors and begin to address the gaps in service provision such that the human rights of offenders are respected, while ensuring the rights of the public are also protected. 


\section{CONCLUSION}

This study revealed that forensic mental health patients in the Pantang Hospital entered through one of three ways; direct entry through the community-based policing system; on order through the court system; and referrals directly from the prison system.

\section{ACKNOWLEDGEMENT}

We thank all participants in the study including the patients, their families, and community Stakeholders; Elvis Akuamoah, a senior mental health preceptor at Pantang Psychiatric Hospital; Dr. Ursula Read, Occupational Therapist and Medical Anthropologist, who helped in the study design and original manuscript editing process; and Dr. Samrat Sengupta, Consultant Forensic Psychiatrist, who helped in the study design. Finally, we are grateful to the Faculty of Forensic Psychiatry, Royal College of Psychiatrists, UK for the grant funding.

\section{REFERENCES}

1. Roberts M, Mogan C, Asari J. An Overview of Ghana's mental health system: results from an assessment using the World Health Organization's Assessment Instrument for Mental Health Systems (WHO-AIMS). Int J Mental Health Syst. 2014; 8 (16). doi: 10.1186/1752-4458-8-16

2. Sipsma H, Ofori-Atta A, Canavan M, Osei-Akoto I, Udry C, Bradley E. Poor mental health in Ghana: Who is at risk? BMC Public Health. 2013; 13(1). doi:

http://dx.doi.org.uml.idm.oclo.org/10.1186/14712458-13-288

3. Roberts M, Asare J, Mogan C, Adjase E, Osea A. The mental health system in Ghana - WHO AIMS report. Accra: Kintampo Project / Ghana Ministry of Health; 2013.

4. Walker, G. Ghana Mental Health Act 846 2012: A qualitative study of the challenges and priorities for implementation. Ghana Medical Journal, 2015; 49(4): 266-274. doi: 10.4314/gmj.v49i4.8

5. Roberts M, Asare J, Mogan C, Adjase E, Osea A. The mental health system in Ghana - WHO AIMS report. Accra: Kintampo Project / Ghana Ministry of Health; 2013.

6. Roberts M, Asare J, Mogan C, Adjase E. An overview of Ghana's mental health system: results from an assessment using the World Health Organization's Assessment Instrument for mental health systems (WHO AIMS). International Journal of Mental Health Systems. 2014; 8:16. doi: 10.1186/17524458-8-16

7. Doku V, Wusu-Takyi A, Awakame J. Implementing the mental health act in Ghana: Any challenges ahead? Ghana Medical Journal, 2012; 46(4): 241250 .

8. Mental Health Act, 2012, Sections 64-79). Retrieved from http://www.refworld.org/pdfid/528f243e4.pdf

9. Government of Ghana, Official Portal. (20 November 2013). Mental Health Authority Board Inaugurated in Ghana. [available at www.ghana.gov.gh/index.php/2012-02-08-08-32-47/general- news/3870mental-health-authority-board-inaugurated-in-accra. 2013; Retrieved on 20/12/2013]

10. A legislative instrument (LI) is the comprehensive document that will be used to guide the implementation of mental health law and the establishment of a mental health fund that will guide the work of the Board.

11. Doku V, Wusu-Takyi A, Awakame J. Implementing the mental health act in Ghana: Any challenges ahead? Ghana Medical Journal 2012; 46(4): 241250

12. Hiday V. Putting Community Risk in Perspective: a Look at Correlations, Causes and Controls. International Journal of Law and Psychiatry 2006; 29: 316331. doi: 10.1016/j.ijlp.2004.08.010

13. Beaupert F. Reflections on policing and mental health in Africa: Integrating and regulating diverse healing and policing systems. In D. Chappell (Editor), Policing and the mentally ill; International perspectives. Advances in police theory and practice series. London, UK; Taylor \& Francis Group. 2013

14. Wolfe (1998, as cited in Beaupert, 2013, p. 294). Beaupert F. Reflections on policing and mental health in Africa: Integrating and regulating diverse healing and policing systems. In D. Chappell (Editor), Policing and the mentally ill; International perspectives. Advances in police theory and practice series. London, UK; Taylor \& Francis Group. 2013

15. World Health Organization (WHO). WHO-AIMS Report on Mental Health System in Ghana: A report of the assessment of the mental health system in Ghana using the World Health Organization - Assessment Instrument for Mental Health Systems (WHO-AIMS). 2011:6. Retrieved from http://www.who.int/mental health/who aims country_reports/ghana who aims report.pdf

16. de Menil V, Osei A, Douptcheva N, Hill A, Yaro P, De-Graft Aikins A. Symptoms of common mental disorders and their correlates among women in Ghana: A population-based study. Ghana Medical Journal 2012; 46(2): 95-103.

17. The Criminal Code (Amendment) Act, 2003, (Act 646). Retrieved from: http://www.refworld.org/pdfid/44bf823a4.pdf

18. Pantang Hospital. 2012 Annual Performance Review, PowerPoint Presentation 9-1, May 2013. 
19. Fereday J, Muir-Cochrane E. Demonstrating rigor using thematic analysis: A hybrid approach of inductive and deductive coding and theme

development. International Journal of Qualitative Methods 2006; 5(1) [available at www.ualberta.ca/ iiqm/backissues/5_1/pdf/fereday.pdf

2006; Retrieved on 15/01/2015. doi: 10.1177/160940690600500107

20. American Psychiatric Association. (2000). Diagnostic and Statistical Manual of Mental Disorders (4th ed., text rev.). Washington, DC: Author.
21. World Health Organization (2004). ICD - 10: International Statistical Classification of Diseases and Related Health Problems, tenth revision, 2nd ed. Geneva: World Health Organization. [available at http://www.who.int/classifications/icd/ICD10_2nd_ed_volume2.pdf Retrieved on 24/09/2018

22. Center for Addiction and Mental Health. What happens inside the forensic mental health system? Retrieved from http://www.camh.ca/en/hospital/health information/the forensic mental_health_system_in_ontario/Pages/forensic_mhontario_whathappens.aspx

Copyright $(\odot$ The Author(s). This is an Open Access article under the CC BY license. 